\title{
4-30-2015
}

\section{One Final Goodbye}

Dennis Baumgardner

Follow this and additional works at: https://aah.org/jpcrr

Part of the Bioethics and Medical Ethics Commons, and the Primary Care Commons

\section{Recommended Citation}

Baumgardner D. One final goodbye. J Patient Cent Res Rev. 2015;2:49-50. doi: 10.17294/2330-0698.1198

Published quarterly by Midwest-based health system Advocate Aurora Health and indexed in PubMed Central, the Journal of Patient-Centered Research and Reviews (JPCRR) is an open access, peer-reviewed medical journal focused on disseminating scholarly works devoted to improving patient-centered care practices, health outcomes, and the patient experience. 


\title{
One Final Goodbye
}

\author{
Dennis J. Baumgardner, MD, Editor-in-Chief | Editorial \\ Department of Family Medicine, Aurora University of Wisconsin Medical Group, Aurora Health Care, Milwaukee, WI
}

In this issue of Journal of Patient-Centered Research and Reviews, Dr. Alyssa Mohorek relates a poignant patient story. Following the death of her patient, Dr. Mohorek, with some apprehension, elected to attend her patient's funeral wake. ${ }^{1}$ This gesture uncovers an important and perhaps neglected issue in contemporary medicine.

There is a small body of recent literature concerning this subject. Borasino et al. reported on a Web-based survey of 204 respondents from the American Academy of Pediatrics Section of Critical Care; among these clinicians, $72 \%$ had attended funeral services and only $2.5 \%$ deemed attendance inappropriate. There was a nonsignificant trend toward such attendance if the respondent was female, or if the respondent felt that follow-up with the family after the death of a child was beneficial to the family. ${ }^{2}$ A vignette-based study of this same cohort indicated that these pediatric clinicians were more apt to attend funerals if they perceived a trusting relationship between the family and the staff. ${ }^{3}$

A survey of 535 Canadian oncologists and palliative care physicians revealed that $95 \%$ of medical oncologists and $96 \%$ of radiation oncologists rarely, if ever, attended funeral memorial services of their patients; however, $30 \%$ of palliative care physicians indicated at least occasional attendance of such services. ${ }^{4}$ Similarly, among 164 respondents to an online survey of oncologic and palliative care specialists from the U.S. Pacific Northwest, $84 \%$ never or rarely attended funeral services. ${ }^{5}$ However, one medical oncologist reported regularly attending funerals and finding the experience "enriching and gratifying" as well as an opportunity to learn about different cultures. ${ }^{6}$

Correspondence: Dennis J. Baumgardner, MD,

1020 N. 12 Street, Suite \#4180, Milwaukee, WI, 53233,

T: 414-219-5191, F: 414-219-3116, Email:

dennis.baumgardner@aurora.org
Regarding primary care clinicians, there appears to be no recent survey data concerning funeral attendance, only mention of the practice in editorials. ${ }^{7-9}$ What are the expectations of family members? A mid-1990s survey of 35 next-of-kins listed on the medical record of a deceased patient in Ohio revealed that $37 \%$ strongly or somewhat expected the family physician to attend the funeral or visitation. ${ }^{10}$

The few primary care physicians who have published experiences attending funerals or wakes, including Dr. Mohorek, have spoken positively about these encounters, but also have expressed some degree of ambivalence. Dr. Jamie Peters, a physician practicing in Minnesota, decided to attend a patient funeral for the first time because "a friendship over time" had developed with the involved couple. His initial hesitation included the risk of being asked clinical questions regarding the deceased. Issues of professional boundaries also had been raised by colleagues. While somewhat uncomfortable with the extra attention paid to him by the family, Dr. Peters noted, "Like the birth of the baby, a funeral is a momentous event in the lives of patients and one that physicians have the honor and privilege to share. A physician's presence at a funeral can be an important last act of care and the first step toward coming to terms with the death of the patient." ${ }^{\prime 7}$ Dr. Lydia Kang of Nebraska experienced feelings of guilt and trepidation in attending her first patient funeral. The deceased had died from a large subdural hematoma following a fall while on warfarin prescribed by the physician. She did not anticipate the warmth and friendliness expressed by the family, and found the amount of flattery uncomfortable, but deemed the experience incredibly positive. She realized how much better she knew the patient after following family conversations about the deceased and viewing pictures of his life. ${ }^{8}$

Dr. Gregory Hood, who began attending funeral visits following his own grandmother's services, 
summarized a number of the issues that lead to clinician ambivalence regarding this activity. He was "reluctant to impose" and too busy. He feared second-guessing his care of the patient. "I think my fears and concerns stemmed from our American approach to life, health, and death," he wrote. "As physicians, we're expected to maintain life at all costs ... death (is) somehow the result of inaction or error. How many doctors, because they're afraid of a suit or of stirring a family's ire, have shied away from attending services or establishing a dialogue with the family?" He concluded, "The art of medicine is the art of healing. My presence at funerals is a natural extension of the healing art, and it serves to comfort and assist the survivors in their own healing. It's an honor and a responsibility. I've found, too, that the family typically makes an extraordinary effort to comfort me as well. After all, I'm also grieving the loss of a patient who had been a friend."

As a family medicine physician who has attended the funeral wakes of many patients with whom I have had more than a casual acquaintance, I have experienced all of the feelings previously described in this editorial. Such attendance is extremely rewarding, however I sometimes fear that I attend more for the personal gain of the "good feelings" received than I do for the benefit of the family. On the other hand, families seem genuinely and enthusiastically pleased by our appearances.

Concerns notwithstanding, I hope to continue this practice. Not doing so presents its own risks. To wit, the family of my last patient who died was admitted while
I was away. Because of the timing and his tertiary care, I was only able to visit the patient once in the hospital before he died, and he was obtunded on that occasion. The family chose to hold private burial services, and I can't help but feel I missed an important moment of personal closure.

\section{REFERENCES}

1. Mohorek A. My time with E. J Patient-Centered Res Rev. 2015;2:73-74.

2. Borasino S, Morrison W, Silberman J, Nelson RM, Feudtner C. Physicians' contact with families after the death of pediatric patients: a survey of pediatric critical care practitioners' beliefs and self-reported practices. Pediatrics. 2008; 122:e1174-8. CrossRef

3. Borasino S, Morrison WE, Silberman J, Feudtner C. Factors associated with pediatric critical care attending follow-up with families after the death of a patient: a national survey with an experimental design. Pediatr Crit Care Med. 2011; 12:622-7. $\underline{\text { CrossRef }}$

4. Chau NG, Zimmermann C, Ma C, Taback N, Krzyzanowska MK. Bereavement practices of physicians in oncology and palliative care. Arch Intern Med. 2009;169:963-71. CrossRef

5. Kusano AS, Kenworthy-Heinige T, Thomas CR Jr. Survey of bereavement practices of cancer care and palliative care physicians in the Pacific Northwest United States. J Oncol Pract. 2012;8:275-81. CrossRef

6. Morris DJ. Medical oncologists' experience in attending a funeral and communicating condolences. Arch Intern Med. 2009;169:1811; author reply 1811-2. CrossRef

7. Peters J. Attending a patient's funeral. Minn Med. 2004;87:32-3.

8. Kang LY. A piece of my mind. The first wake. JAMA. 2009;301:467-8. CrossRef

9. Hood GA. Why I go to patients' funerals. Med Econ. 2003;80:88.

10. Dangler LA, O'Donnell J, Gingrich C, Bope ET. What do family members expect from the family physician of a deceased loved one? Fam Med. 1996;28:694-7.

(C) 2015 Aurora Health Care, Inc. 